\title{
VÝUKA TECHNOLOGIE
}

УДК 372.83

DOI: 10.24045/ap.2017.2.5

ФИНАНСОВОЕ ПРОСВЕЩЕНИЕ МОЛОДЕЖИ: АКТУАЛЬНЫЙ ОПЫТ

С. Ю. Гурьянова

Кандидат экономических наук, дочент

ORCID: 0000-0002-0439-7821

учитель

Домодедовский лицей № 3

им. Героя Советского Союза

Ю. П. Максимова

г. Домодедово, Россия

FINANCIAL EDUCATION OF YOUTH: ACTUAL EXPERIENCE

S. Yu. Guryanova

\author{
Candidate of Economic Science \\ associate professor \\ ORCID: 0000-0002-0439-7821 \\ Teacher of history and social science \\ economics and law \\ Domodedovo Lyceum № 3 \\ named after Hero of the Soviet Union \\ Yu. P. Maksimov \\ Domodedovo, Russia
}

\begin{abstract}
The author of the article shares practical experience in solving the actual problem of raising the level of financial literacy of students of general education organizations. The methodical development of the lesson of financial literacy integrated into the course "Social Studies» 11 class is presented. The important role of the use of gaming technologies in the educational space is underlined. The question of application of intelligence maps (Mind maps) in the educational process is considered.
\end{abstract}

Keywords: financial literacy; modern educational technologies; Mind maps; bank; deposit; credit.

Предлагаю вашему вниманию методическую разработку урока-игры «Финансы вокруг нас» интегрированного в курс «Обществознание»
11 класс, проводимый с использованием элементов информационнокоммуникационных технологий. 
Будет Россия образована, будет и богата.

И. И. Янжул

Цели и задачи урока:

1. Продолжить формирование финансовой грамотности у учащихся.

2. Повторить и закрепить учебный материал о функциях банков.

3. Обобщить и систематизировать знания учащихся о банковских вкладах и зависимости доходности от многих условий, сформировать представление о сути кредита, объяснить необходимость оценки своего финансового состояния и возможностей при взятии кредита.

4. Продолжить развитие творческих, интеллектуальных и коммуникативных способностей учащихся.

5. Содействовать формированию навыков работы в команде.

\section{Тип урока:}

1. По классификации С. А. Ежовой - урок применения знаний и формирования умений и навыков;

2. По классификации А. А. Вагина - урок применения знаний;

3. По классификации П. В. Горы - повторительно-обобщающий урок.

Оборудование урока:

1. Мультимедийная презентация «Финансы вокруг нас».

2. Выставка книг «Финансовая грамотность - путь к успеху!».

3. Аудиозапись куплетов Мефистофеля из оперы «Фауст» Ш. Гуно («Люди гибнут за металл...»).

4. Аудиозапись песни «Money, Money, Money» в исполнении группы ABBA.

5. Грамоты для награждения команд.
6. Компьютер, мультимедийный проектор, интерактивная доска SMART Board и оборудование к ней, планшетные ПК.

Формы обучения: индивидуальная, фронтальная, групповая, коллективная.

Методы обучения: словесный, практический.

Основные понятия и термины: финансы, инфляция, банк, депозит, кредит, рассчетно-кассовые операции.

Планируемые образовательные результаты:

Объем освоения и уровень владения компетенциями:

Научатся: оценивать надежность банка, сравнивать условия по депозитам и кредитам для выбора оптимального варианта решения своих финансовых задач; анализировать, делать выводы, отвечать на вопросы, высказывать собственную точку зрения.

Получат возможность научиться: формулировать познавательные цели; владеть способами совместной работы в группах; инициативно сотрудничать в поиске и сборе информации; анализировать события, факты с целью выделения признаков; приходить к общему решению; развивать способность к самооценке.

Компоненты культурнокомпетентностного опыта / приобретенная компетентность:

Учебно-познавательная и коммуникативная компетенщии:

Умеют: выполнять творческие задания; работать с различными источниками информации; выступать с устными сообщениями; представ- 
лять собственную точку зрения; выступать устно с результатами своего исследования с помощью компьютерных средств; работать в группах; распределять обязанности; проявляют способность к взаимодействию; проводить оценку своей учебной деятельности

Форма проведения урока: дидактическая игра.

\section{Этапы дидактической игры:}

I. Представление команд.

II. «Познавая мир финансов» (Разминка).

III. «Финансовая мозаика» (Конкурс «Найди слово!»).

IV. «Выдающиеся финансисты России: время, личность, судьба» (Домашнее задание: представление и защита мультимедийной презентации).

V. «Умные финансы». (Решение задач, составление алгоритмов принятия финансовых решений).

VI. «Увлекательные финансы» (Конкурс капитанов команд).

VII. «От финансовой грамотности - к финансовой культуре»

(Мотив «Человек и деньги» в художественных произведениях).

VIII. «Финансы - это просто» (Составление интеллект-карты).

\section{Ход дидактической игры}

Вступительное слово учителя:

Необходимость повышения финансовой грамотности диктуется временем. Сегодня, когда термины «банк», «депозит», «кредит», «инфляция» ежедневно звучат в СМИ и используются в разговорной речи, не каждый молодой человек знает основы финансовой грамотности.
Весьма показательны результаты международного сравнительного исследования финансовой грамотности, проводимого Организацией экономического сотрудничества и развития (ОЭСР), опубликованного в 2016 году: Россия заняла лишь 25 место среди 30 стран мира, участвовавших в исследовании, по уровню финансовой грамотности [9].

Все это доказывает, что изучение школьниками основ финансовой грамотности - реальная необходимость современности.

Наш урок будет проходить в форме дидактической игры. Игра, как показывает опыт, способствует соединению финансовых реалий жизни и учебного материала, создает особую среду, которую можно определить как пространство социализации личности.

\section{Объяснение правил игры:}

В игре принимают участие учащиеся 11 класса, разделенные на две команды. Каждая из команд в ходе игры будет работать над общими для всех заданиями, либо над специальными заданиями, объединенными общей темой и сравнительно одинаковыми по сложности.

В ходе игры идет работа по обобщению и повторению темы «Финансы вокруг нас». Выявляется победитель (команда). Ученики, активно принимавшие участие в игре, получают оценки.

Жюри ведет подсчет баллов по пятибалльной системе за каждое задание, подводит итоги в конце игры и называет победителя.

Состав жюри дидактической игры: администрация школы, родите- 
ли учеников, учащиеся старших классов.

Дидактическая игра приобретает характер общественного смотра знаний.

\section{Этапы дидактической игры}

Звучит аудиозапись куплетов Мефистофеля из оперь «Фауст» Ш. Гуно («Люди гибнут за металл...»).

\section{I. Представление команд} (название, эмблема, девиз).

За две недели до урока класс делится на две команды, в каждой из них определяется капитан. Команды придумывают свое название, готовят девиз, эмблему и получают домашнее задание.

\section{II. «Познавая мир финан-} сов» (Разминка).

\section{Задание команде А:}

В стихотворении «Деньги» И. Ф. Богданович есть такие строки: «Беда, коль денег нет; но что за сила тянет К богатству всех людей?

Без денег счастье вянет, И жизнь без них скучна, живи хотя сто лет; Пока твой век минет - беда! коль денег нет...»

Что такое деньги? Как вы думаете, почему человек не может прожить без денег?
(Деньги - это особый товар, выполняющий роль всеобщего эквивалента при обмене товаров)

\section{Задание команде Б:}

В произведении А. С. Пушкина «Скупой рыцарь» говорится:

«Деньги? - деньги

Всегда, во всякий возраст

нам пригодны;

Но юноша в них ищет слуг

проворных

И не жалея шлет туда, сюда.

Старик же видит в них друзей

надежных

И бережет их как зеницу ока...»

Какие функции денег Вы знаете?

Как вы понимаете, что означают слова «деньги - слуги», «деньги друзья»?

(Функиии денег: мера стоимости, средство обращения, средство накопления)

III. «Финансовая мозаика» (Конкурс «Найди слово!»).

Выполните задание на интерактивной доске.

\section{Задание команде А:}

Найдите слово из семи букв, означающее деньги или ценные бумаги, вносимые в кредитное учреждение для хранения или со специальной целью (по вертикали) (депозит). 


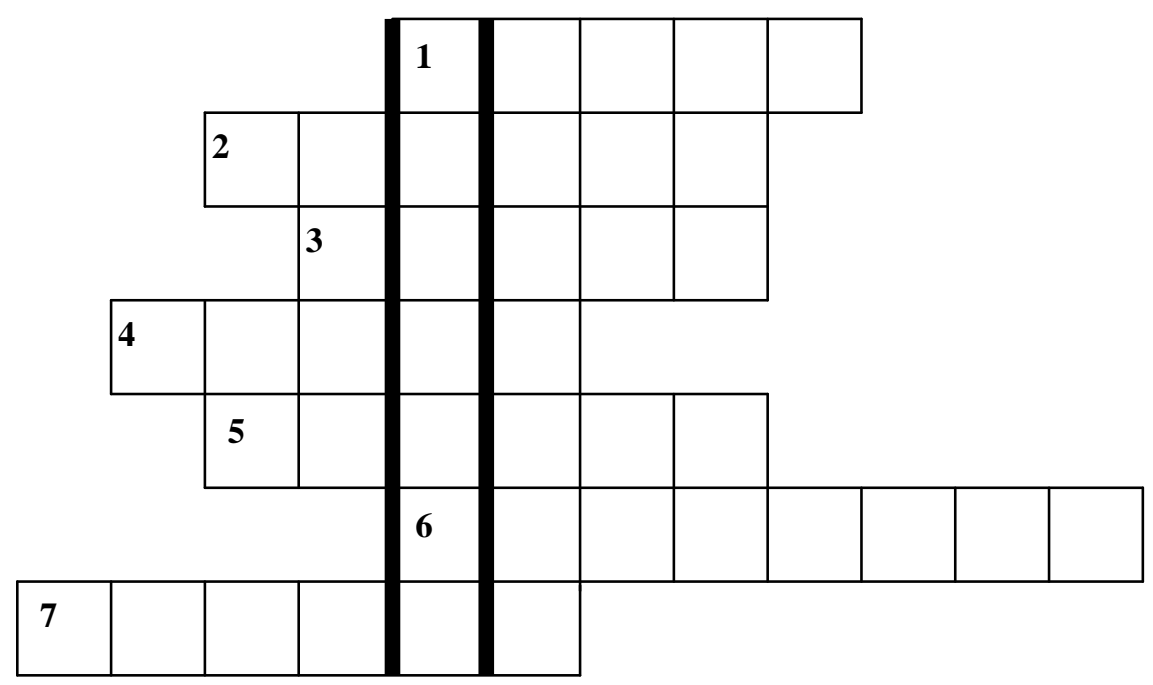

По горизонтали:

1. Деньги или материальные ценности, получаемые от предприятия или какого-нибудь рода деятельности - (доход).

2. Предоставление денег или товаров в долг на определенный срок, как правило, с уплатой процентов и на условиях возвратности - (кредит).

3. Желание потребителя купить конкретный товар, подкрепленное способностью оплатить покупку (спрос).

4. Обязательный платеж, взимаемый государством с каждого производителя товаров и услуг, владельца того или иного имущества и иных получателей дохода - (налог).

5. Любая деятельность по производству и обмену товаров и услуг, осуществляемая частными лицами или организациями в целях получения прибыли - (бизнес).

6. Процесс обесценивания денег, который проявляется в форме роста цен на товары и услуги - (инфляиия).

7. Денежная единица какой либо страны, находящаяся в обращении внутри страны - (валюта).

\section{Задание команде Б:}

Найдите слово из семи букв, означающее систему экономических отношений, в процессе которых происходит формирование, распределение и использование централизованных и децентрализованных фондов денежных средств (по вертикали) - (финансы). 


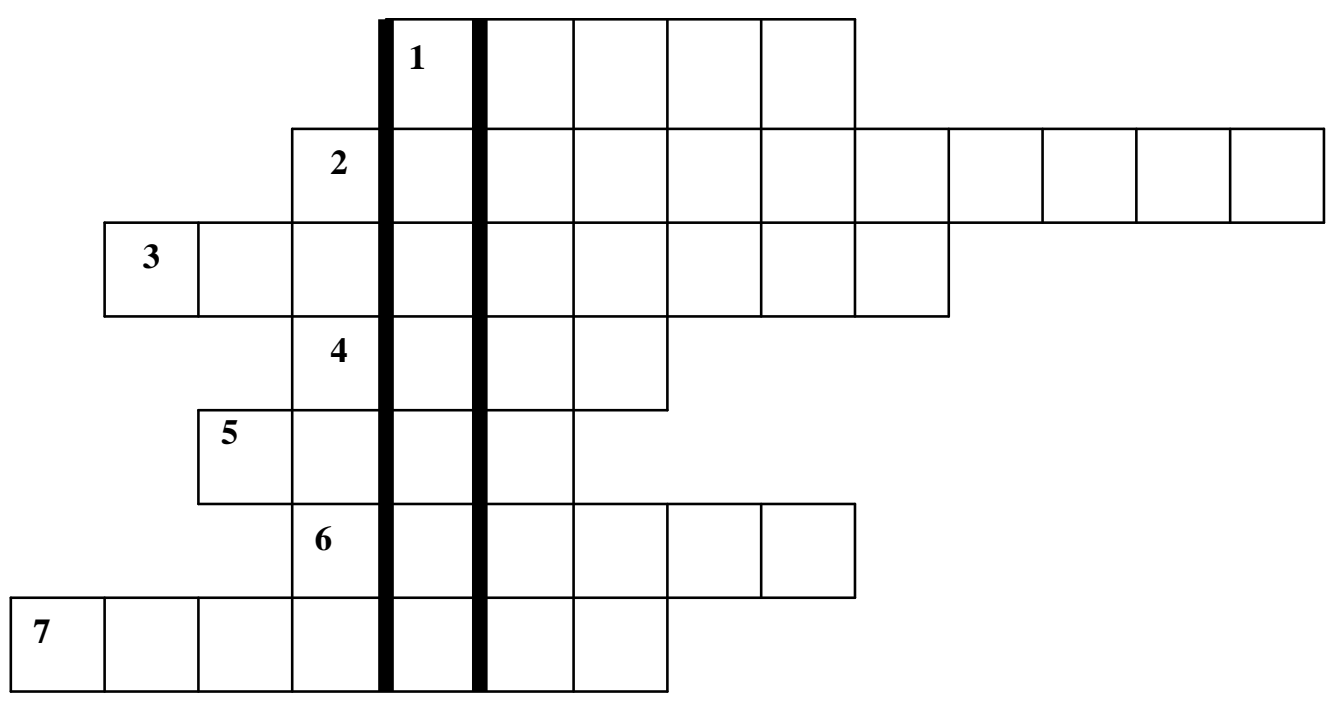

\section{По горизонтали:}

1. Коммерческая организация, приобретающая экономические ресурсы для производства и продажи товаров и услуг в целях получения прибыли - (фирма).

2. Способность быстрого превращения активов в средства платежа - (ликвидность).

3. Наука, изучающая, как наилучшим образом использовать ограниченные ресурсы в целях удовлетворения неограниченных потребностей - (экономика).

4. Финансово-кредитная организация, производящая разнообразные виды операций с деньгами и ценными бумагами и оказывающая финансовые услуги правительству, юридическим и физическим лицам - (банк).

5. Стоимость товара или услуги, выраженная в деньгах - (цена).

6. Нематериальные блага, обладающие определенной ценностью и предоставляемые за плату - (услуги).
7. Превышение доходов от продажи товаров и услуг над расходами на производство и реализацию этих товаров - (прибыль $)$.

IV. «Выдающиеся финансисты России: время, личность, судьба» (Домашнее задание).

За две недели до урока команды A и Б получили домашнее задание.

Подготовьте мультимедийную презентацию «Выдающиеся финансисты России: время, личность, судьба» (Посошков И. Т., Сперанский М. М., Канкрин Е. Ф., Рейтерн М. Х., Витте С. Ю. и др.) (8-10 слайдов).

На уроке команды $A$ и $Б$ представляют свои проекты, защищают их и отвечают на вопросы.

V. «Умные финансы» (принятие финансовых решений).

5.1. Решите финансовые задачи.

Задание команде А:

5.1.1. В дни летних каникул Антон заработал 60 тысяч рублей. Он планировал воспользоваться этими деньгами через три года, когда у его 
мамы будет юбилей. Чтобы деньги не обесценились, находясь в копилке, Антон решил разместить их на банковский депозит.

Банк «Роза» предлагает ставку 7 \% годовых с начислением процентов в конце срока.

Банк «Мимоза» предлагает ставку 6 \% годовых с начислением и капитализацией процентов в конце каждого года.

Какое из предложений для трехлетнего депозита будет выгоднее для Антона? Обоснуйте свой ответ.

Ответ: предложение банка «Роза» выгоднее (12 600 руб. >11460 руб.).

5.1.2. Мама хочет купить Саше горный велосипед.

Магазин «Север» предлагает эту модель велосипеда за 19000 рублей с беспроцентной рассрочкой на год, так что ежемесячный платеж составит 1583 руб. 33 коп.

Магазин «Юг» предлагает эту же модель велосипеда за 15000 рублей, но в кредит на год под 20 \% годовых.

Мама обратилась к Саше с просьбой, рассчитать, где им более выгодно сделать покупку. Что ответил Саша?

Ответ: предложение магазина «Юг» выгоднее (18000 руб. < 19000 руб.).

\section{Задание команде Б:}

5.1.3. За творческую победу в конкурсе «Одаренные дети» Анна получила грант мэра города в размере 50 тысяч рублей. Она планировала воспользоваться этими деньгами через два года, для обучения в университете. Чтобы деньги не обесценились, Анна решила разместить их на банковский депозит.
Банк «Береза» предлагает ставку 8 \% годовых с начислением процентов в конце срока.

Банк «Рябина» предлагает ставку 9 \% годовых с начислением и капитализацией процентов в конце каждого года.

Какое из предложений для двухлетнего депозита будет выгоднее для Анны? Обоснуйте свой ответ.

Ответ: предложение банка «Рябина» выгоднее (9 405 руб. >8000 руб.).

5.1.4. Бабушка хочет подарить внуку экипировку юного хоккеиста.

Магазин «Запад» предлагает эту экипировку за 20000 рублей с беспроцентной рассрочкой на год, так что ежемесячный платеж составит 1666 руб. 67 коп.

Магазин «Восток» предлагает эту же экипировку за 18000 рублей, но в кредит на год под 25 \% годовых.

Бабушка обратилась к внуку с просьбой, рассчитать, где им более выгодно сделать покупку. Что ответил внук?

Ответ: предложение магазина «Запад» выгоднее (20000 руб. < 22500 руб.).

5.2. Составьте алгоритм принятия финансового решения, для этого используйте Интернет-ресурсы.

\section{Задание команде А:}

Составьте алгоритм «Оптимальная депозитная стратегия».

Ответ:

1. Ознакомьтесь с информацией о процентных ставках по депозитам в разных банках.

2. Убедитесь, что банк, в который вы собираетесь сделать вклад, является участником системы стра- 
хования вкладов (имеет соответствуюшую лицензию Банка России).

3. Определите привлекательный для вас вид депозита.

4. Внимательно изучите депозитный договор.

5. Храните деньги в разных банках.

6. Определите цели своих сбережений и комбинируйте сроки и ставки в соответствии с этими цуелями.

\section{Задание команде Б:}

Составьте алгоритм «Как выбрать наиболее выгодный кредит?».

Oтвет:

1. Определите вид кредита, который Вам необходим.

2. Ознакомьтесь с информацией об условиях кредитования.

3. Сравните кредитные предложения разных банков и составьте шорт-лист лучиих предложений.

4. Уточните все условия кредитования непосредственно в банке.

5. Рассчитайте размер полной стоимости кредита и сумму переплатьл.

6. Изучите график платежей и оцените насколько он вам удобен.

VI. «Увлекательные финансы» (Конкурс капитанов команд).

6.1. «Финансовый калейдоскоп» $[1,7,8]$.

На интерактивной доске соотнесите крылатые выражения, связанные с деньгами, и их определения.

Задание капитану команды А:

Деньги хорошие слуги, но плохие хозяева.
Деньги не должны всецело властвовать над людьми и делать их алчныли и бездунными.

Не было ни гроша, да вдруг алтын.

Так говорят при неожиданном везении, удачном приобретении или случайном выигрыше. (Грош - мелкая монета стоимостью в разные времена от полкопейки до двух копеек. Алтын, или алтынник, - более ценная, золотая монета).

Копейка рубль бережет.

Говорится в тех случаях, когда кому-то советуют быть побережливее, поэкономнее, не тратить деньги попусту на всякие мелочи.

\section{Задание капитану команды Б:}

Не в деньгах счастье, а в добром согласье.

Деньги далеко не всегда приносят людям счастье. Но если человек умеет толково распорядиться своим богатством, и при этом не жаден, помогает другим людям, то он сам получает от этого удовольствие и к нему люди относятся подоброму.

Ближняя копеечка дороже дальнего рубля.

Лучше небольшая, но верная выгода на месте, чем может быть, и большая, но на стороне.

Слову - вера, хлебу - мера, деньгам - счет.

Жить нужно так: говорить правду, хлеба брать ровно столько, чтобы съесть, тратить только на необходимые нужды.

\section{2. «Знаток банкнот».}

С каким городом можно познакомиться с помощью российской купюры достоинством: 
Задание капитану команды А:

Десять рублей (Красноярск).

Сто рублей (Москва).

Пять тысяч рублей (Хабаровск).

Задание капитану команды Б:

Пятьдесят рублей (СанктПетербург).

Пятьсот рублей (Архангельск).

Одна тысяча рублей (Ярославль).

VII. «От финансовой грамотности - к финансовой культуре».

Общее задание командам А и Б:

Приведите примеры художественных произведений (литературы, живописи, музыки и др.) на тему «Человек и деньги».

(Отвечает каждый участник команды по очереди, если не знает, ход переходит другой команде.)

Ответ:

- У. Шекспир «Венециианский купец».

- Ж. Б. Мольер «Скупой».

- Оноре де Бальзак «Гобсек».

- А. С. Пушкин «Скупой рыцарь».

- А. С. Пушкин «Пиковая дама».

- И. А. Крылов «Бедный богач».

- A. Н. Островский «Бедность не порок».

- Ф. М. Достоевский «Преступление и наказание».

- Ф. М. Достоевский «Идиот».

- T. Драйзер «Американская трагедия».

- В. Г. Распутин «Деньги для Марии».

- К. Массейс «Меняла с женой».

- Б. М. Кустодиев «Яблоко и сторублевка».

- Б. М. Кустодиев «Купеи, считающий деньги».

- В. Е. Маковский «Крах банка».
- B. Е. Маковский «Скупой рыuарь».

- Ш. Гуно «Фауст».

- П. И. Чайковский «Пиковая дама» и $\partial$.

VIII. «Финансы - это просто». Общее задание командам А и Б:

Составьте интеллект-карту (Mind map) по теме «Финансы вокруг нас» [5].

Как вы помните, интеллект-карта имеет четыре существенные отличительные черты: а) объект внимания/изучения кристаллизован в центральном образе; б) основные темы, связанные с объектом внимания/изучения, расходятся от центрального образа в виде ветвей; в) ветви, принимающие форму плавных линий, обозначаются и поясняются ключевыми словами или образами. Вторичные идеи также изображаются в виде ветвей, отходящих от ветвей более высокого порядка; то же справедливо для третичных идей и т. д.; г) ветви формируют связанную узловую систему [3].

После составления интеллекткарты по теме «Финансы вокруг нас» ответьте на вопросы:

1. Что такое банк? Каковы основные функции банков?

2. Чем депозит отличается от вклада до востребования?

3. Каковы основные преимущества и недостатки депозита, его место в личном финансовом плане?

4. Что такое банковский кредит, какие виды кредитов вы знаете?

5. Из чего складываются платежи по кредиту? 
6. Для чего люди используют денежные переводы?

\section{Итог урока:}

Ребята, урок-игра «Финансы вокруг нас» показал не только ваши знания, но и умение применять их на практике. Многие задания были проблемными, носили творческий характер, но, проявив смекалку, вы справились с ними.

Изучая курс «Финансовая грамотность» вы научились отвечать на вопросы: как устроен современный банк? Как оценивать надежность банка? Как сравнивать условия по депозитам и кредитам для выбора оптимального варианта решения своих финансовых задач? эти вопросы сама жизнь ставит перед гражданами России.

На нашем уроке мы стремились сформировать стереотипы поведения, старались подготовить вас к самостоятельной взрослой жизни, помогли вам в определенной степени застраховаться от финансовых ошибок и потерь в будущем. Все это позволит вам чувствовать себя уверенно и независимо в финансовом мире!

Звучит аудиозапись припева песни «Money, Money, Money» в исполнении группь АВBA.

Жюри подводит итоги дидактической, обучающей игры.

Команда победитель в дидактической, обучающей игре награждается почетной грамотой. Наиболее отличившимся участникам команд выставляются оценки.

Рефлексия.
Домашнее задание: составьте синквейн по теме урока.

\section{Библиографический список}

1. Большой толковый уникальный иллюстрированный словарь для детей. Фразеологизмы. Пословицы и поговорки. Афоризмы и крылатые слова / авт.сост. С. В. Волков, С. Н. Зигуненко, С. В. Истомин. - М. : Восток-Запад, 2012. $-254 \mathrm{c}$.

2. Брехова Ю. В. Финансовая грамотность: материалы для учащихся. 10-11 классы общеобразоват. орг. - М.: ВИТА-ПРЕСС, 2014. - 400 c.

3. Бьюзен Т., Бьюзен Б. Супермышление / пер. с англ. Е. А. Самсонов. Мн. : Попурри, 2003.

4. Горяев А., Чумаченко В. Основы финансовой грамотности : учебное пособие. - М. : СмартБук: И-трейд, 2016. $264 \mathrm{c}$.

5. Гурьянова С. Ю. Российская «Национальная платформа открытого образования» - шаг в будущее высшей школы // Ежемесячный научнопрактический журнал «Качество. Инновации. Образование» Номер 2 (129), февраль 2016. - С. 3-9.

6. Лавренова Е. Б. Финансовая грамотность: методические рекомендации для учителя. 10-11 классы общеобразоват. орг., экономический профиль. М. : ВИТА-ПРЕСС, 2014. - 224 с.

7. Розе Т. В. Большой толковый словарь пословиц и поговорок русского языка для детей. - М. : ОЛМА Медиа Групп, 2011. - 224 c.

8. Уникальный иллюстрированный толковый словарь пословиц и поговорок для детей / авт.-сост. С. Н. Зигуненко. - М. : АСТ: Астрель, 2010. - 206 с.

9. OECD/INFE International Survey of Adult Financial Literacy Competencies: 2016: [сайт]. URL: http://www.oecd.org/daf/fin/financialeducation/OECD-INFE-InternationalSurvey-of-Adult-FInancial-Literacy- 
Competencies.pdf (дата обращения: 26.05.2017).

10. Официальный сайт Министерства финансов РФ: [сайт]. URL: http://minfin.ru/ (дата обращения: 26.05.2017).

11. Официальный сайт Министерства финансов Московской области: [сайт]. URL: http://mf.mosreg.ru/ (дата обращения: 26.05.2017).

12. Официальный сайт Центрального банка Российской Федерации: [сайт]. URL: http://cbr.ru (дата обращения: 26.05.2017).

\section{Bibliograficheskij spisok}

1. Bol'shoj tolkovyj unikal'nyj illjustrirovannyj slovar' dlja detej. Frazeologizmy. Poslovicy i pogovorki. Aforizmy i krylatye slova / avt.-sost. S. V. Volkov, S. N. Zigunenko, S. V. Istomin. - M. : Vostok-Zapad, 2012. - $254 \mathrm{~s}$.

2. Brehova Ju. V. Finansovaja gramotnost': materialy dlja uchashhihsja. 10-11 klassy obshheobrazovat. org. - M.: VITAPRESS, 2014. - $400 \mathrm{~s}$.

3. B'juzen T., B'juzen B. Supermyshlenie / per. s angl. E. A. Samsonov. - Mn. : Popurri, 2003.

4. Gorjaev A., Chumachenko V. Osnovy finansovoj gramotnosti : uchebnoe posobie. - M. : SmartBuk: I-trejd, 2016. - $264 \mathrm{~s}$.

5. Gur'janova S. Ju. Rossijskaja «Nacional'naja platforma otkrytogo obrazovanija»- shag V budushhee vysshej shkoly // Ezhemesjachnyj nauch- no-prakticheskij zhurnal «Kachestvo. Innovacii. Obrazovanie» Nomer 2 (129), fevral' 2016. - S. 3-9.

6. Lavrenova E. B. Finansovaja gramotnost': metodicheskie rekomendacii dlja uchitelja. 10-11 klassy obshheobrazovat. org., jekonomicheskij profil'. M. : VITA-PRESS, 2014. - $224 \mathrm{~s}$.

7. Roze T. V. Bol'shoj tolkovyj slovar' poslovic i pogovorok russkogo jazyka dlja detej. - M. : OLMA Media Grupp, 2011. - $224 \mathrm{~s}$.

8. Unikal'nyj illjustrirovannyj tolkovyj slovar' poslovic i pogovorok dlja detej / avt.-sost. S. N. Zigunenko. - M. : AST: Astrel', 2010. - 206 s.

9. OECD/INFE International Survey of Adult Financial Literacy Competencies: 2016: [sajt]. URL: http://www.oecd.org/daf/fin/financialeducation/OECD-INFE-InternationalSurvey-of-Adult-FInancial-LiteracyCompetencies.pdf (data obrashhenija: 26.05.2017).

10. Oficial'nyj sajt Ministerstva finansov RF: [sajt]. URL: http://minfin.ru/ (data obrashhenija: 26.05.2017).

11. Oficial'nyj sajt Ministerstva finansov Moskovskoj oblasti: [sajt]. URL: http://mf.mosreg.ru/ (data obrashhenija: 26.05.2017).

12. Oficial'nyj sajt Central'nogo banka Rossijskoj Federacii: [sajt]. URL: http://cbr.ru (data obrashhenija: 26.05.2017).

(C) Гурьянова С. Ю., 2017. 